\title{
Feasibility, acceptability and efficacy of a school-based prevention programme for eating disorders: cluster randomised controlled trial
}

\author{
Helen Sharpe, Ilka Schober, Janet Treasure and Ulrike Schmidt
}

\section{Background}

Body image dissatisfaction during adolescence is common but not benign. School-based interventions have the potential for wide reach, but scalability of previous programmes is limited by a reliance on external facilitators.

\begin{abstract}
Aims
To assess the acceptability, feasibility and efficacy of a teacher-delivered body image intervention.
\end{abstract}

\section{Method}

A pilot clustered randomised controlled trial in which 16 classes of adolescent girls were allocated to a 6-session body image programme $(n=261)$, or usual curriculum control $(n=187)$ (registration: ISRCTN42594993).

\section{Results}

Students in the intervention group had significantly improved body esteem and self-esteem and reduced thin-ideal internalisation. Effects for body esteem and thin-ideal internalisation were maintained for 3 months. There were no group differences for eating pathology, peer factors or depression. Acceptability, feasibility and efficacy varied between schools.

\section{Conclusions}

Teacher-delivered body image lessons have promise but further work is needed to increase efficacy and make interventions suitable across a range of schools.

\section{Declaration of interest}

None.
Body dissatisfaction during adolescence is common but not benign. Between 17 and 33\% of adolescents report body dissatisfaction, with the figure higher for girls than boys. ${ }^{1,2}$ Body dissatisfaction is a major public health concern because of its association with an array of negative outcomes, ranging from depression and eating disorders, to cosmetic surgery use, over- and under-exercising, obesity and unhealthy weight loss behaviours such as smoking. ${ }^{1,3}$ As such, body dissatisfaction has been the focus of government policy in a number of countries. ${ }^{3-5}$

Schools offer an opportunity for prevention of body dissatisfaction, as programmes can be delivered across the population prior to the increase in body image dissatisfaction seen in late adolescence. ${ }^{6}$ Previous work has shown that school-based interventions can reduce body dissatisfaction and its precursors. ${ }^{7,8}$ However, delivery has usually been by clinical psychologists, ${ }^{7,8}$ who are an expensive and limited resource in schools.

A further difficulty in this area has been the reliance on nonevidence-based programmes. For example, in the UK, Media Smart (www.mediasmart.org.uk/resources/bodyimage), a media literacy programme, has been widely disseminated without evidence for its efficacy. ${ }^{3}$ This is problematic as, aside from the potential for wasted resources, some trials of interventions for eating disorders ${ }^{9}$ and depression ${ }^{10}$ in schools have found evidence of detrimental effects. There is therefore a need for safe and effective, evidence-based body image interventions that are deliverable by school teachers.

The current study aimed to address this dearth of evidence through reporting on the first pilot cluster randomised controlled trial of a teacher-delivered body image programme in UK secondary schools. The intervention was developed in conjunction with school teachers and young people, ${ }^{11}$ and addressed risk factors for body image dissatisfaction, namely: thin-ideal internalisation, peer factors, depression and low self-esteem. ${ }^{12-15}$ The content had some similarities to previous successful programmes, ${ }^{7,8}$ but was unique in including a positive psychology approach in lessons tackling depression and low self-esteem, and in being designed for delivery by teachers. The objectives of this pilot study were to determine the efficacy, acceptability and feasibility of this intervention.

\section{Method}

\section{Trial design}

The study was a cluster randomised controlled trial (registration: ISRCTN42594993). Classes of secondary school students were allocated by unrestricted randomisation to an intervention or to a curriculum-as-usual control. Participants were assessed with questionnaire measures at pre-intervention, post-intervention and 3-month follow-up.

\section{Participants}

Participants were adolescents enrolled in UK secondary schools. Schools were eligible to participate if they had students in years 8 and/or 9, and had a sufficiently flexible timetable to manage random allocation of lessons. Schools were excluded if they catered specifically for students with special educational needs.

All classes in years 8 and 9 in participating schools were eligible for inclusion. Participants were eligible to take part if they received parental/carer consent, and were deemed by school staff to have sufficient English language ability to comprehend assent procedures and manage written questionnaires.

All data were collected within the school setting. School staff administered questionnaires within regular school hours, based on protocols provided by the research team.

\section{Intervention}

The intervention, Me, You \& Us, consisted of six 50-minute lessons designed to be delivered by teachers to intact classes of participating students. The content of the six lessons was outlined in an intervention manual (available from the authors), with 
accompanying student workbooks and Powerpoint slides. Lessons one and two focused on media literacy, with an exploration of how beauty has been defined throughout history, where our ideals of beauty come from, learning to critically analyse media images, and taking action (e.g. writing to a Member of Parliament) about images that might promote body dissatisfaction. Lessons three and four focused on peer interactions, with an exploration of fat talking (a ritualised form of negative commentary about weight and shape), ${ }^{16}$ why we might fat talk and how to stop it, as well as activities on giving and receiving compliments from others. Finally, lessons five and six drew on positive psychology principles ${ }^{17}$ boosting mood and self-esteem through considering the nature of our personal strengths, what makes us happy, noticing positives, and showing gratitude to others.

These lessons were delivered by students' usual teachers, who were invited to take part in training. All teachers agreed. Training consisted of a standardised 2 hour session, which covered psychoeducation about eating disorders, a review of how to use the manual, lesson content and discussion of challenging elements of the programme.

Participants in the control group received their curriculum as usual. The content of these lessons was not determined by the trial but consisted of whatever had been planned by teachers for that period. Content of the control lessons was not recorded.

\section{Outcomes}

All outcomes were assessed using participant self-report questionnaires. Demographic information and eating disorder screening was obtained 1 week prior to the intervention period (preintervention). Demographic information included age, ethnicity and highest level of parental education. Presence of potential eating disorder at baseline was assessed using the Eating Disorder Diagnostic Scale, ${ }^{18}$ which identifies DSM-IV diagnostic criteria for anorexia nervosa, bulimia nervosa and binge eating disorder. ${ }^{19}$

All outcome measures were administered at pre-intervention, post-intervention and at 3-month follow-up. The primary outcome was body esteem, assessed by the Body Esteem Scale for Adults and Adolescents. ${ }^{20}$ The secondary outcomes were: presence of binge eating (at least once a week for 3 months) or compensatory behaviours (one of the following: vomiting, laxative/ diuretic use, meal skipping or excessive exercise, at least once a week for 3 months), assessed using the Eating Disorder Diagnostic Scale; ${ }^{18}$ thin-ideal internalisation, assessed using the Internalisation subscale of the Sociocultural Attitudes Towards Appearance Scale- $3 ;^{21}$ appearance conversations with peers, assessed using the Appearance Conversations with Friends Scale; ${ }^{22}$ peer support, assessed using the Friend subscale of the Multidimensional Scale of Perceived Social Support; ${ }^{23}$ depressive symptoms, assessed using the Depression subscale of the short version of the Depression, Anxiety and Stress Scale; ${ }^{24}$ and self-esteem, assessed using the item 'How positively do you feel about yourself?'.

Acceptability of the programme for students was assessed using two items: 'How much did you enjoy Me, You \& Us?' and 'How useful did you find Me, You \& Us?'. Fidelity of delivery of the intervention was assessed through lesson observations. Two lessons were observed in each school and these were rated regarding adherence to planned content. Each activity in the intervention guide was rated as being 'completed' or 'not completed'. Free text was used to note whether any additional material was covered.

\section{Sample size}

Sample size calculations were conducted using $G^{\star}$ Power $3 .^{25}$ Given the lack of previous data on this intervention, the inflation factor for this trial was based on a generic estimate of a small intracluster correlation (ICC $=0.05) .{ }^{26}$ We assumed a small effect size $(d=0.20)$, based on previous similar trials, ${ }^{7}$ and set power at 0.80 . Assuming a 1:1 ratio between the groups, the basic sample size requirement was 394 participants per group, which increased to 926 per group when the estimated inflation factor was taken into account.

\section{Randomisation and masking}

For pragmatic considerations, random allocation was carried out at the level of existing classes. An online random number generator $^{27}$ was used to create a random allocation sequence. Randomisation was unrestricted. One researcher (H.S.) carried out the enrolment of classes, the generation of the random allocation sequence and the allocation of classes to conditions. Participants' allocation to trial arm was based on their class membership. Informed consent for participants was obtained from all participants' parents/carers following randomisation. In addition, participants provided written assent post-randomisation, when completing the pre-intervention questionnaire measures.

Given the nature of the trial design, it was not possible to mask school staff or student participants to their allocated condition. The trial arms were similar in that they took the form of usual school lessons, but distinct in that the intervention arm included materials produced outside of the school (e.g. the student workbooks), which would have been identifiable as such to participating staff and students. Researchers were also unmasked. However, risk of bias from lack of researcher masking was low, as the researchers did not conduct assessments.

\section{Statistical analyses}

All analyses were conducted using STATA, Version 12 for Mac. Continuous outcome variables were assessed for normal distribution, resulting in two severely skewed outcomes (depressive symptoms, peer support) being dichotomised. The dichotomy was based on a cut-off score of 14 for depressive symptoms, ${ }^{24}$ and the median for peer support.

All analyses were based on originally assigned groups. In order to account for the clustered design of this trial, linear and logistic mixed models were used. These included fixed effects for group, time point, baseline values of the outcome, and random intercepts for school, class and participant ID. For all models, the intracluster correlations for school and class were very small (ICC ranging from $<0.001$ to 0.01$)$. Likelihood ratio tests indicated that inclusion of these random intercepts did not significantly improve the fit of the model and so they were removed. Following model development, model assumptions were checked. Residuals were checked for normality, constant variance and outliers through observation of residual plots.

Mixed models are robust to data that are missing at random if values of observed factors found to be associated with missing data are included as covariates in the model. ${ }^{28}$ All participants may be included in the model, regardless of having complete data. Missing data in this trial arose from missed time points (13\% of participants missed at least one time point due to school absence), and from incomplete questionnaires (ranging from $0 \%$ to $17 \%$ across different outcomes). A series of Bonferroni-adjusted chi-squared tests, $t$-tests and Wilcoxon rank sum tests were performed in order to determine whether any of the observed data were associated with missingness. For the primary outcome, missing data were associated with school, ethnicity, age and preintervention appearance conversations and for the secondary outcomes missing data were associated with school, age and 
pre-intervention peer support. These factors were therefore included as covariates in the mixed models.

Effect sizes (Cohen's $d$ ) for continuous outcomes were calculated by computing differences in the adjusted means between the intervention group and control group (at post-intervention and 3-month follow-up) and dividing this by the standard deviation for the whole sample at baseline.

The extent of reliable and clinically significant change in the primary outcome was calculated using methods reported by Jacobson \& Truax. $^{29}$ Reliable change indices for the Body Esteem Scale for Adults and Adolescents were based on internal consistency estimates from this sample $(\alpha=0.94)$. Clinical cut offs were based on the midpoint between clinical populations and normal populations. The clinical norms used were taken from Mendelson $e t a l^{30}$ (mean 1.21, s.d. =0.70) and the non-clinical norms from Mendelson \& White ${ }^{31}$ (mean 2.07, s.d.=1.04).

\section{Results}

\section{Participant flow and recruitment}

Flow of participants through the trial is shown in Fig. 1. Random allocation of 16 classes from 3 participating schools resulted in 261 students in the intervention arm and 187 students in the control arm. Following pre-intervention assessments eight participants were identified as possible cases of eating disorders. These participants were excluded from further analyses. No participants dropped out of the trial.

The trial was conducted between May 2011 and June 2012. Recruitment of schools and participants occurred between May and September 2011. Delivery of the intervention occurred between October and December 2011 in Schools A and B. School $\mathrm{C}$ had an unexpected timetable disruption in the middle of delivery and so the intervention occurred between October 2011 and February 2012, with follow-ups completed in June 2012.

\section{Baseline data}

All three schools were state-funded girls' schools. School A was a comprehensive school in outer London with an above-average free school meal eligibility rate ( $24 \%$, a proxy for social deprivation). This school also had the greatest range of participants from ethnic minority backgrounds, with $77 \%$ of participants identifying themselves as being from Black and minority ethnic (BME) backgrounds. School B was a selective school in outer London, with low free school meal eligibility (2\%) and roughly equal numbers of students identifying as being White as being from a BME background. School C was a selective school in the east of

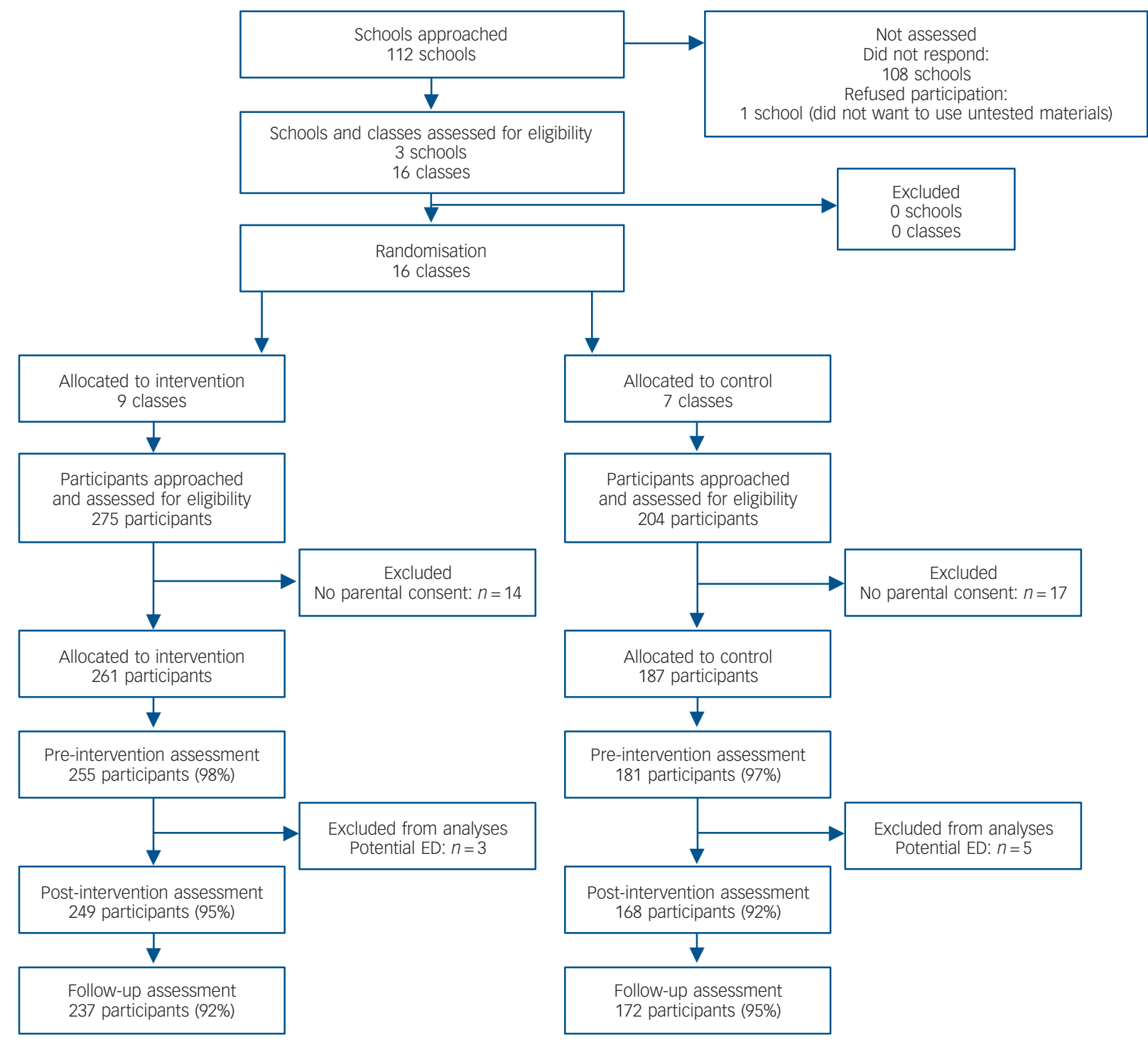

Fig. 1 CONSORT diagram showing flow of participants through the trial. ED, eating disorder. 
England, with low free school meal eligibility and the majority of students $(71 \%)$ defining their ethnic background as White. Participating students in Schools A and C were in year 8, and participating students in School B were in year 9.

Participant characteristics for each group at pre-intervention are shown in Table 1. There were no significant differences between the groups at baseline on any of the demographic measures or outcomes.

\section{Acceptability and feasibility}

Approximately three-quarters of students were either neutral or positive about how enjoyable the intervention lessons were, and about two-thirds were neutral or positive about the usefulness of the lessons. As Fig. 2 shows, acceptability varied significantly between the three schools (useful: $\chi^{2}(8)=37.65, P<0.001$; enjoyable: $\chi^{2}(8)=63.85, P<0.001$ ), with the vast majority of participants from Schools A and $\mathrm{C}$ responding neutral or positively to the lessons (84-97\%), whereas participants in School B responded more ambivalently (49-53\% neutral or positive).

Feasibility of teacher delivery of material, assessed through fidelity to the intervention manual, also varied between the schools: teachers in School A and School C delivered 78\% of the intervention activities across the two observed lessons, whereas teachers in School B delivered 50\% of intervention activities.

\section{Body esteem}

Adjusted means for body esteem in each group are shown in Table 2 and in Fig. 3. The main effect of group for body esteem was marginal $(b=0.09$, s.e. $=0.05, P=0.08)$. Further exploration using Wald tests showed a marginal difference between the groups at post-intervention $\left(\chi^{2}(1)=3.17, P=0.07\right)$ and a significant difference between the groups at 3 -month follow-up $\left(\chi^{2}(1)=7.60\right.$, $P=0.006)$. At both time points the intervention group had higher body esteem than the control group. The effect sizes for these group differences, shown in Table 2, were small.

The extent of reliable and clinically significant change in body esteem between baseline and post-intervention is shown in Tables 3 and 4 . As changes between baseline and 3-month follow-up were largely the same as those at post-intervention, only changes to post-intervention are shown here.

Based on the cut-off score calculated as 1.56, 34 (17\%) participants in the intervention group and $26(19 \%)$ participants in the control group were initially in the clinical range for body esteem (Table 3). A greater percentage of participants showed clinically

\begin{tabular}{|c|c|c|c|}
\hline & $\begin{array}{c}\text { Intervention group } \\
n(\%)\end{array}$ & $\begin{array}{c}\text { Control group } \\
n(\%)\end{array}$ & $p^{a}$ \\
\hline Age, years: mean (s.d.) & $13.06(0.59)$ & $12.99(0.54)$ & 0.28 \\
\hline \multicolumn{4}{|l|}{ Ethnicity, $n(\%)$} \\
\hline White & $133(53)$ & $79(47)$ & \\
\hline Black & $37(15)$ & $35(21)$ & \\
\hline Asian & $43(17)$ & $32(19)$ & \\
\hline Other & $34(14)$ & $20(12)$ & 0.34 \\
\hline \multicolumn{4}{|l|}{ Parental education, $n$ (\%) } \\
\hline Primary & $2(1)$ & $0(0)$ & \\
\hline Secondary & $57(24)$ & $39(23)$ & \\
\hline University & $182(76)$ & $132(78)$ & 0.68 \\
\hline Body esteem, mean (s.d.) & $2.30(0.75)$ & $2.27(0.70)$ & 0.73 \\
\hline Presence of binge eating, $n$ (\%) & $16(7)$ & $13(8)$ & 0.61 \\
\hline Use of compensatory behaviours, $n$ (\%) & $94(38)$ & $62(35)$ & 0.63 \\
\hline Internalisation of thin-ideals, mean (s.d.) & $23.09(9.42)$ & $20.94(8.63)$ & 0.02 \\
\hline Appearance conversations, mean (s.d.) & $11.75(4.59)$ & $11.73(4.53)$ & 0.99 \\
\hline Low peer support, $n(\%)$ & $97(43)$ & $85(50)$ & 0.15 \\
\hline High depressive symptoms, $n(\%)$ & $37(16)$ & $19(12)$ & 0.21 \\
\hline Self-esteem, mean (s.d.) & $3.42(1.00)$ & $3.52(0.87)$ & 0.25 \\
\hline
\end{tabular}

\begin{tabular}{|c|c|c|c|c|}
\hline & $\begin{array}{l}\text { Intervention group } \\
\text { Mean (s.e.) }\end{array}$ & $\begin{array}{l}\text { Control group } \\
\text { Mean (s.e.) }\end{array}$ & $P$ & $d$ \\
\hline \multicolumn{5}{|l|}{ Body esteem } \\
\hline Post-intervention & $2.31(0.32)$ & $2.22(0.39)$ & 0.07 & 0.12 \\
\hline 3-month follow-up & $2.37(0.32)$ & $2.22(0.39)$ & 0.006 & 0.19 \\
\hline \multicolumn{5}{|c|}{ Thin-ideal internalisation } \\
\hline Post-intervention & $21.94(0.47)$ & $23.47(0.57)$ & 0.04 & 0.17 \\
\hline 3-month follow-up & $21.57(0.48)$ & $22.99(0.55)$ & 0.05 & 0.16 \\
\hline \multicolumn{5}{|c|}{ Appearance conversations } \\
\hline Post-intervention & $11.73(0.25)$ & $11.73(0.25)$ & 0.90 & 0.01 \\
\hline 3-month follow-up & $12.68(0.21)$ & $12.39(0.23)$ & 0.34 & 0.06 \\
\hline \multicolumn{5}{|l|}{ Self-esteem } \\
\hline Post-intervention & $3.52(0.06)$ & $3.33(0.07)$ & 0.04 & 0.20 \\
\hline 3-month follow-up & $3.47(0.06)$ & $3.34(0.07)$ & 0.15 & 0.13 \\
\hline
\end{tabular}




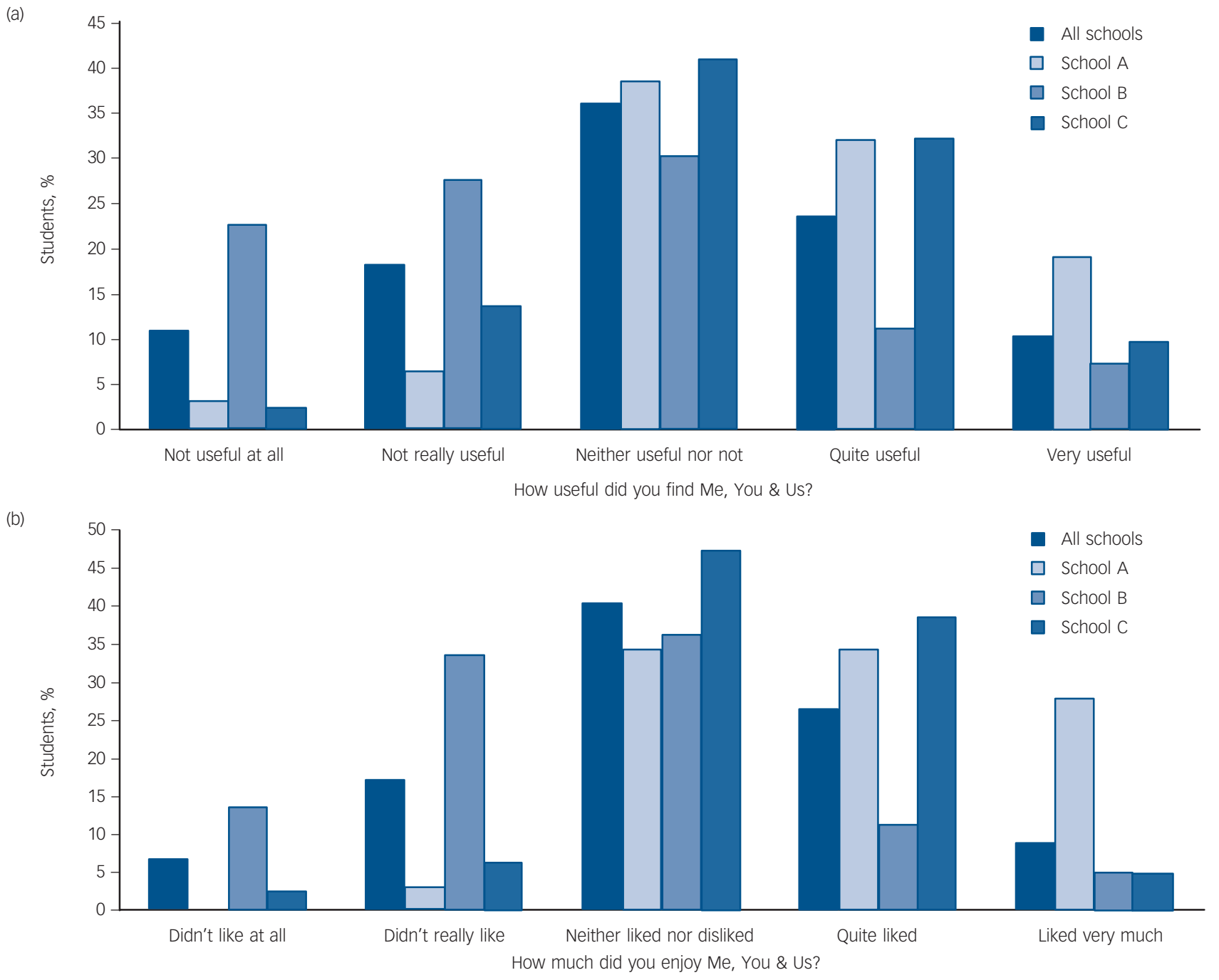

Fig. 2 Bar graphs showing the percentages of participants that found the intervention useful (a), and found the intervention enjoyable (b) by school.

significant improvements (i.e. moving from the clinical range to the normal range) in the intervention group (50\%) compared with the control group (38\%), although this difference was not statistically significant $\left(\chi^{2}(1)=0.79, P=0.37\right)$. There was greater reliable change in the direction of improvement in the intervention group (32\%) compared with the control group (7\%), a difference that was statistically significant $\left(\chi^{2}(1)=5.97, P=0.02\right)$.

Turning to those participants who were initially in the normal range for body esteem, there were no participants in either the intervention group or control group that showed clinically significant worsening of body esteem, suggesting no harm to body esteem caused by the intervention (Table 4). All of the reliable change observed in this group was in the direction of improved body esteem. A greater proportion of participants in the intervention group showed reliable improvements in body esteem (12\%) compared to the control group (4\%), a difference that was statistically significant $\left(\chi^{2}(1)=6.58, P=0.01\right)$.

\section{Secondary outcomes}

The adjusted means for the continuous secondary outcomes are shown in Table 2. There was a significant main effect of group for thin-ideal internalisation $(b=-1.53$, s.e. $=0.74, P=0.04)$ and self-esteem $(b=0.19$, s.e. $=0.09, P=0.04)$, but not for appearance conversations $(b=-0.04$, s.e. $=0.32, P=0.90)$. For thin-ideal internalisation, post hoc testing showed significant differences between the groups at post-intervention $\left(\chi^{2}(1)=4.21\right.$, $P=0.04)$, which was maintained at the 3 -month follow-up $\left(\chi^{2}(1)=3.84, P=0.05\right)$. In both cases the intervention group showed lower thin-ideal internalisation compared with the control group. For self-esteem, the comparisons between the groups at each of the time points revealed a significant difference at postintervention $\left(\chi^{2}(1)=4.36, P=0.04\right)$, but this difference was lost at 3 -month follow-up $\left(\chi^{2}(1)=2.07, P=0.15\right)$. The percentages of participants reporting each of the binary secondary outcomes are shown in Tables 5 and 6 . There were no main effects of group for binge eating (odds ratio $(\mathrm{OR})=4.44,95 \%$ CI $0.39-51.22$, $P=0.23)$, compensatory behaviours $(\mathrm{OR}=1.69,95 \%$ CI $0.74-3.89$, $P=0.22)$, peer support $(\mathrm{OR}=1.40,95 \% \mathrm{CI} 0.64-3.06, P=0.40)$ or depressive symptoms $(\mathrm{OR}=1.49,95 \% \mathrm{CI} 0.46-4.78, P=0.50)$.

\section{Moderating effect of school}

Given the differences in fidelity and acceptability between schools, additional analyses were conducted to explore whether there was a moderating effect of school on intervention efficacy. To do this, the mixed models were re-run including a group $\times$ school interaction term. The group $\times$ school interaction was significant for body esteem $\left(\chi^{2}(1)=4.24, P=0.04\right)$ and for internalisation $\left(\chi^{2}(1)=4.21, \quad P=0.04\right)$, but not for any other outcomes $\left(\chi^{2}(1)<0.11, P>0.75\right)$. Further exploration of body esteem revealed a significant main effect of group in School A 


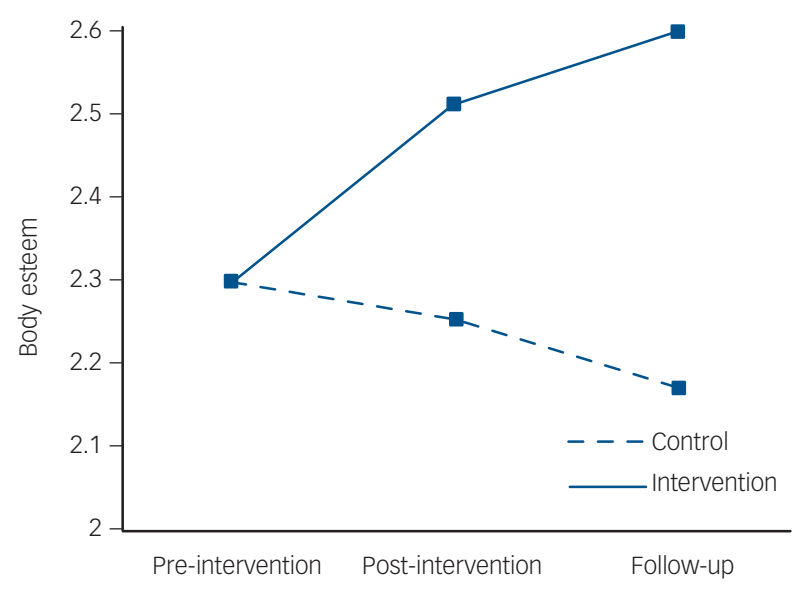

Fig. 3 Adjusted means for body esteem at pre-intervention, post-intervention and 3-month follow-up, by group.

$\left(\chi^{2}(1)=14.05, P=0.002\right)$, but not in School B $\left(\chi^{2}(1)=0.04\right.$, $P=0.83)$ or School C $\left(\chi^{2}(1)=2.38, P=0.12\right)$. In contrast, further exploration for thin-ideal internalisation revealed a significant main effect of group in School B $\left(\chi^{2}(1)=7.77, P=0.005\right)$, but not in School A $\left(\chi^{2}(1)=0.56, P=0.45\right)$ or School C $\left(\chi^{2}(1)=0.26\right.$, $P=0.61)$.

\section{Discussion}

This study was the first randomised controlled trial of a teacherdelivered body image intervention in UK secondary schools. The results provide preliminary evidence that it is feasible and acceptable to have body image lessons delivered by teachers in schools. They also show that this approach can benefit students' body esteem, although broader hypothesised effects such as reduced eating disorder and depressive symptoms were not found.

\section{Main findings}

There were significant effects of the intervention on body esteem and this difference was maintained over the 3 months of follow-up. Importantly, there was no evidence of harm (i.e. decreases in body esteem) from the programme. In terms of the results' clinical significance, there were more reliable improvements in body esteem in the intervention group compared with the control group, but no differences in students showing clinically significant changes. This was to be expected as the universal nature of this intervention meant that few participants began the trial within the clinical range. Small but significant improvements were found for participants' thin-ideal internalisation - the extent to which they endorsed social ideals associated with thinness - and self-esteem. The effects on thin-ideal internalisation were still present after 3 months, but those for self-esteem were lost. There were no intervention effects observed for eating pathology, appearance conversations, peer support or depressive symptoms.

Between-school variations were found across outcomes in body esteem and thin-ideal internalization, as well as in the acceptability and feasibility of the approach. It should be noted that the moderation analyses were post hoc and so considerably lacking in power. In the current trial, no corrective action was taken if staff deviated from the intervention during observations, so more active supervision may be one approach to improve outcomes. The lower acceptability and fidelity in School B could be because participants were older in this school or the training may have not met needs of these teachers. Further understanding of what determines variations in delivery across school sites will be essential for successful scalability of this approach.

Comparison with previous work is difficult as most body image interventions in schools have been delivered by facilitators rather than teachers. ${ }^{7,8}$ In line with interventions conducted outside of the UK, the effect sizes on body image were small. ${ }^{32,33}$ Several other studies have found no effects on body image from teacher-delivered interventions, ${ }^{34-36}$ which are at odds with the findings from this trial. Replication of this study would therefore be necessary to confirm efficacy of this approach.

\begin{tabular}{|c|c|c|c|c|c|c|}
\hline & \multicolumn{3}{|c|}{ Intervention group } & \multicolumn{3}{|c|}{ Control group } \\
\hline & \multicolumn{2}{|c|}{ Reliable change } & \multirow[b]{2}{*}{$\begin{array}{l}\text { Total } \\
n(\%)\end{array}$} & \multicolumn{2}{|c|}{ Reliable change } & \multirow[b]{2}{*}{$\begin{array}{l}\text { Total } \\
n(\%)\end{array}$} \\
\hline & $\begin{array}{c}\text { Yes } \\
n(\%)\end{array}$ & $\begin{array}{c}\text { No } \\
n(\%)\end{array}$ & & $\begin{array}{c}\text { Yes } \\
n(\%)\end{array}$ & $\begin{array}{c}\text { No } \\
n(\%)\end{array}$ & \\
\hline No clinically significant change & $1(3)^{b}$ & $16(47)$ & $17(50)$ & $0(0)$ & $16(62)$ & $16(62)$ \\
\hline Clinically significant improvement & $10(29)$ & 7 (21) & $17(50)$ & $2(8)$ & $8(30)$ & $10(38)$ \\
\hline Total & $11(32)$ & $23(69)$ & $34(100)$ & $2(8)$ & $24(92)$ & $26(100)$ \\
\hline
\end{tabular}

\begin{tabular}{|c|c|c|c|c|c|c|}
\hline & \multicolumn{3}{|c|}{ Intervention group } & \multicolumn{3}{|c|}{ Control group } \\
\hline & \multicolumn{2}{|c|}{ Reliable change } & \multirow[b]{2}{*}{$\begin{array}{l}\text { Total } \\
n(\%)\end{array}$} & \multicolumn{2}{|c|}{ Reliable change } & \multirow[b]{2}{*}{$\begin{array}{l}\text { Total } \\
n(\%)\end{array}$} \\
\hline & $\begin{array}{c}\text { Yes } \\
n(\%)\end{array}$ & $\begin{array}{c}\text { No } \\
n(\%)\end{array}$ & & $\begin{array}{c}\text { Yes } \\
n(\%)\end{array}$ & $\begin{array}{c}\text { No } \\
n(\%)\end{array}$ & \\
\hline No clinically significant change & $20(12)^{b}$ & $142(88)$ & $162(100)$ & $4(4)^{b}$ & $110(96)$ & $114(100)$ \\
\hline Clinically significant worsening & $0(0)$ & $0(0)$ & $0(0)$ & $0(0)$ & $0(0)$ & $0(0)$ \\
\hline Total & $20(12)$ & $142(88)$ & $162(100)$ & $4(4)$ & $110(96)$ & $114(100)$ \\
\hline
\end{tabular}


Table 5 Counts and percentages showing group differences in binge eating and compensatory behaviours at post-intervention and 3-month follow up

\begin{tabular}{|c|c|c|c|c|}
\hline & \multicolumn{2}{|c|}{ Control group, $n$ (\%) } & \multicolumn{2}{|c|}{ Intervention group, $n$ (\%) } \\
\hline & No & Yes & No & Yes \\
\hline \multicolumn{5}{|l|}{ Binge eating } \\
\hline Baseline & $152(92)$ & $13(8)$ & $228(93)$ & $16(7)$ \\
\hline Post-intervention & $154(96)$ & $7(4)$ & 214 (94) & $14(6)$ \\
\hline 3-month follow-up & $165(96)$ & $6(4)$ & $224(96)$ & $9(4)$ \\
\hline \multicolumn{5}{|c|}{ Compensatory behaviours } \\
\hline Baseline & $113(65)$ & $62(35)$ & $115(62)$ & $94(38)$ \\
\hline Post-intervention & $105(64)$ & $60(36)$ & $138(60)$ & $93(40)$ \\
\hline 3-month follow-up & $129(75)$ & $42(24)$ & $162(70)$ & $70(30)$ \\
\hline
\end{tabular}

Table 6 Counts and percentages showing group differences in peer support and depressive symptoms at post-intervention and 3-month follow up

\begin{tabular}{|c|c|c|c|c|}
\hline & \multicolumn{2}{|c|}{ Control group, $n(\%)$} & \multicolumn{2}{|c|}{ Intervention group, $n(\%)$} \\
\hline & Low & High & Low & High \\
\hline \multicolumn{5}{|l|}{ Peer support } \\
\hline Baseline & $85(50)$ & $86(50)$ & $97(43)$ & $131(57)$ \\
\hline Post-intervention & $68(45)$ & $82(55)$ & 82 (39) & $129(61)$ \\
\hline 3-month follow-up & $84(51)$ & $81(49)$ & $94(44)$ & $121(56)$ \\
\hline \multicolumn{5}{|l|}{ Depressive symptoms } \\
\hline Baseline & $143(88)$ & $19(12)$ & $190(84)$ & $37(16)$ \\
\hline Post-intervention & $126(84)$ & $24(16)$ & $177(82)$ & $40(18)$ \\
\hline 3-month follow-up & $133(80)$ & $33(20)$ & $178(81)$ & 75 (19) \\
\hline
\end{tabular}

Several of the null findings from this trial have also been reported elsewhere, suggesting the need for considerable advances in this field. For example, effects on depressive symptoms are generally not observed for these relatively brief, teacher-delivered interventions for body image, despite relevant content. ${ }^{32,34}$ School interventions focusing specifically on depression are typically more intensive ${ }^{37}$ and so these programmes may lack the dosage to produce effects. Producing changes in eating pathology has also been elusive for teacher-delivered programmes. ${ }^{34,35}$ That said, Favaro et $a l^{38}$ observed a reduced 1-year incidence of bulimia nervosa following a teacher-delivered intervention $(0 \%, n=38)$ compared with a control group $(3.3 \%, n=91)$. In this trial the training of the teachers was intensive (taking place over 5 weeks), suggesting that greater training could be of importance for the current intervention.

\section{Limitations}

A number of factors limit the conclusion of this trial. A weakness of using random allocation based on classes was that there was a potential for control group contamination. There was also no means of assessing whether any contamination had occurred. Using school as the unit of randomisation in larger future trials would help to alleviate this problem.

A second limitation was the lack of an active control condition. Potentials for sham interventions that could serve as control conditions include activities such as expressive writing ${ }^{39}$ or healthy eating programmes. ${ }^{40}$ Furthermore, there was no means of assessing whether intervention-relevant content was delivered as part of the control lessons. However, observed between-group differences imply that a distinction was maintained between the trial arms.

Third, statistical power was a limitation of this pilot trial. The original power calculations for this study suggested that approximately 900 participants were needed per group (although the ICC was overestimated). Post hoc estimates of achieved power using the effect size for the primary outcome at 3-month follow-up $(d=0.19)$, show that the trial only had $49 \%$ power to detect group differences.

The limit on the sample size for the trial was due to low recruitment of schools, rather than of students within schools (indeed, 94\% invited students took part). Recruitment was demanding: over 100 schools were sent letters outlining the study, and 3 agreed to take part. Reasons for non-response and characteristics of non-participating schools are not known, but the extent to which findings can be generalised to other schools needs to be investigated. The low school recruitment in this trial may reflect on the feasibility of this approach. However, it is worth bearing in mind that the main burden from participation arose from the evaluation protocol (assessment, etc.) and not the programme per se. The mass uptake of programmes such as Media Smart in the UK suggests that there is a great demand for teacher resources of this kind.

Fourth, a nuanced understanding of the results was limited by a coarse measure of intervention fidelity. Lesson observations provided a rudimentary indication of the intervention fidelity but could be greatly improved, especially as these results suggested that fidelity to intervention material was less satisfactory in one school. A gold standard system would be to audio record all sessions and have these rated by independent researchers.

Finally, the follow-up period in this trial was limited to 3 months. Valuable information about whether effects are maintained in the medium-long term would be gained from future studies over longer time periods.

\section{Generalisability}

A strength of this study was that the schools represented a range of participants, including many from BME backgrounds. It is of significance that the trial was conducted in state-funded schools and delivered by regular school staff. The teachers involved in delivery included men and women, those specialising in health/ personal development education and those who were not specialists in this area. A limit on the generalisability of these findings is that all three schools were girls' schools and so were 
not representative of the typical UK secondary school, which is co-educational.

\section{Implications}

This study suggests that a teacher-delivered programme for body image dissatisfaction is, broadly speaking, feasible, acceptable and efficacious. Nonetheless, substantial further work is needed in refining the content of the current body image lessons, increasing their efficacy across a range of outcomes, improving the flexibility with which they may be used in different schools, and exploring the best ways of providing training for teachers so that they are adequately prepared for this role. In addition, further trials will be essential to replicate these findings and to ensure that materials provided for schools are a safe and effective use of school resources in tackling body dissatisfaction.

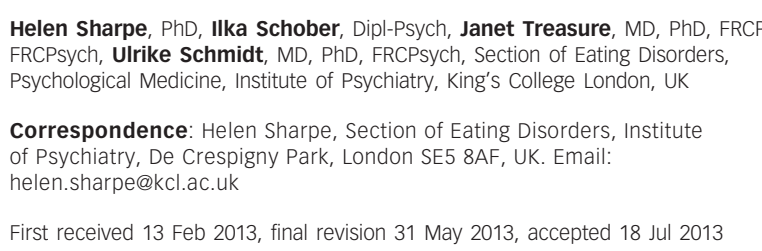

\section{Funding}

This article presents independent research commissioned by the National Institute for Health Research (NIHR) under its Programme Grants for Applied Research scheme (RP-PG-0606-1043). The views expressed in this publication are those of the author(s) and not necessarily those of the NHS, the NIHR or the Department of Health. This work was supported by a grant from the NIHR Biomedical Research Centre for Mental Health, South London and Maudsley NHS Foundation Trust and Institute of Psychiatry, King's College London.

\section{Acknowledgements}

We would like to thank the staff, students and parents from participating schools for their support in conducting this study.

\section{References}

1 Neumark-Sztainer D, Paxton SJ, Hannan PJ, Haines J, Story M. Does body satisfaction matter? Five-year longitudinal associations between body satisfaction and health behaviors in adolescent females and males. J Adolesc Health 2006; 39: 244-51.

2 Calzo JP, Sonneville KR, Haines J, Blood EA, Field AE, Austin SB. The development of associations among body mass index, body dissatisfaction, and weight and shape concern in adolescent boys and girls. $J$ Adolesc Health 2012; 51: 517-23.

3 All Parliamentary Group on Body Image. Reflections of Body Image. TSO (The Stationery Office), 2012.

4 Office for Youth. Sizing Up Body Image: What South Australia's Young People Say About Body Image. Office for Youth, 2011.

5 Department of Children and Youth Affairs. How We See It: Report of a Survey on Young People's Body Image. Government Publications, 2012.

6 Eisenberg ME, Neumark-Sztainer D, Paxton SJ. Five-year change in body satisfaction among adolescents. J Psychosom Res 2006; 61: 521-7.

7 Wilksch SM, Wade TD. Reduction of shape and weight concern in young adolescents: a 30-month controlled evaluation of a media literacy program. J Am Acad Child Adolesc Psychiatry 2009; 48: 652-61.

8 Richardson SM, Paxton SJ. An evaluation of a body image intervention based on risk factors for body dissatisfaction: a controlled study with adolescent girls. Int J Eat Disord 2010; 43: 112-22.

9 Carter JC, Stewart DA, Dunn VJ, Fairburn CG. Primary prevention of eating disorders: Might it do more harm than good? Int J Eat Disord 1997; 22: 167-72.

10 Stallard P, Sayal K, Phillips R, Taylor JA, Spears M, Anderson R, et al. Classroom based cognitive behavioural therapy in reducing symptoms of depression in high risk adolescents: pragmatic cluster randomised controlled trial. BMJ 2012; 345: e6058.

11 Sharpe H, Damazer K, Treasure J, Schmidt U. What are adolescents' experiences of body dissatisfaction and dieting, and what do they recommend for prevention? A qualitative study. Eat Weight Disord 2013; 18: 133-41.

12 Jacobi C, Hayward C, de Zwaan M, Kraemer HC, Agras WS. Coming to terms with risk factors for eating disorders: application of risk terminology and suggestions for a general taxonomy. Psychol Bull 2004; 130: 19-65.

13 Stice E. Risk and maintenance factors for eating pathology: a meta-analytic review. Psychol Bull 2002; 128: 825-48.

14 Stice $\mathrm{E}$, Shaw $\mathrm{H}$. Role of body dissatisfaction in the onset and maintenance of eating pathology: a synthesis of research findings. J Psychosom Res 2002; 53: 985-93.

15 Sharpe $\mathrm{H}$, Naumann $\mathrm{U}$, Treasure J, Schmidt $\mathrm{U}$. Is fat talking a causal risk factor for body dissatisfaction? A systematic review and meta-analysis. Int J Eat Disord 2013; Jul 1, doi: 10.1002/eat.22151 [Epub ahead of print].

16 Nichter M. Fat Talk: What Girls and their Parents say about Dieting. Harvard University Press, 2001.

17 Seligman MEP. Flourish: A New Understanding of Happiness and Well-Being. Nicholas Brealey, 2011.

18 Stice E, Telch CF, Rizvi SL. Development and validation of the Eating Disorder Diagnostic Scale: brief self-report measure of anorexia, bulimia, and bingeeating disorder. Psychol Assess 2000; 12: 123.

19 American Psychiatric Association. Diagnostic and Statistical Manual of Mental Disorders (4th edn) (DSM-IV). APA, 1994.

20 Mendelson BK, Mendelson MJ, White DR. Body-esteem scale for adolescents and adults. J Pers Assess 2001; 76: 90-106.

21 Thompson JK, Van den Berg P, Roehrig M, Guarda AS, Heinberg U. The sociocultural attitudes towards appearance scale-3 (SATAQ-3): development and validation. Int J Eat Disord 2004; 35: 293-304.

22 Jones DC, Vigfusdottir TH, Lee Y. Body image and the appearance culture among adolescent girls and boys. J Adolesc Res 2004; 19: 323-39.

23 Zimet G, Dahlem NW, Zimet SG, Farley GK. Psychometric characteristics of the Multidimensional Scale of Perceived Social Support. J Pers Assess 1988; 55: 610-7.

24 Lovibond SH, Lovibond PF. Manual for the Depression Anxiety and Stress Scales. Psychology Foundation, 1995.

25 Faul F, Erdfelder E, Lang AG, Buchner A. G* Power 3: A flexible statistical power analysis program for the social, behavioral, and biomedical sciences. Behav Res Methods 2007; 39: 175-91.

26 Hox J. Multilevel Analysis: Techniques and Applications. Routledge, 2002

27 Haahr M. Random.Org. 2012 [cited 2010 August]; Available from: http:// www.random.org/.

28 West BT, Welch KB, Galecki AT. Linear Mixed Models: A Practical Guide using Statistical Software. CRC Press, 2007.

29 Jacobson NS, Truax P. Clinical significance: a statistical approach to defining meaningful change in psychotherapy research. J Consult Clin Psychol 1991; 59: 12.

30 Mendelson BK, McLaren L, Gauvin L, Steiger H. The relationship of selfesteem and body esteem in women with and without eating disorders. Int J Eat Disord 2002; 31: 318-23.

31 Mendelson BK, White DR. Manual for the Body-Esteem Scale for Adolescents and Adults. Concordia University, 1997.

32 O'Dea JA, Abraham S. Improving the body image, eating attitudes, and behaviors of young male and female adolescents: a new educational approach that focuses on self-esteem. Int J Eat Disord 2000; 28: 43-57.

33 Steiner-Adair C, Sjostrom L, Franko DL, Pai S, Tucker R, Becker AE, et al. Primary prevention of risk factors for eating disorders in adolescent girls: learning from practice. Int J Eat Disord 2002; 32: 401-11.

34 Ghaderi $\mathrm{A}$, Mårtensson $\mathrm{M}$, Schwan $\mathrm{H}$. "Everybody's Different": a primary prevention program among fifth grade school children. Eat Disord 2005; 13 : 245-59.

35 Phelps L, Sapia J, Nathanson D, Nelson L. An empirically supported eating disorder prevention program. Psychol Sch 2000; 37: 443-52.

36 McVey G, Tweed S, Blackmore E. Healthy Schools-Healthy Kids: a controlled evaluation of a comprehensive universal eating disorder prevention program. Body Image 2007; 4: 115-36.

37 Calear AL, Christensen H. Systematic review of school-based prevention and early intervention programs for depression. J Adolesc 2010; 33: 429-38.

38 Favaro A, Zanetti T, Huon G, Santonastaso P. Engaging teachers in an eating disorder preventive intervention. Int J Eat Disord 2005; 38: 73-7.

39 Stice $E$, Shaw $H$, Burton $E$, Wade $E$. Dissonance and healthy weight eating disorder prevention programs: a randomized efficacy trial. J Consult Clin Psychol 2006; 74: 263

40 Baranowski MJ, Marion $\mathrm{MH}$. Testing the efficacy of an eating disorder prevention program. Int J Eat Disord 2001; 29: 119-24. 